Marquette University

e-Publications@Marquette

$1-1-2001$

\title{
Investment Performance Comparison Between Roth and Traditional Individual Retirement Accounts
}

George Kutner

Marquette University, george.kutner@marquette.edu

Lloyd Doney

Marquette University, lloyd.doney@marquette.edu

James Trebby

Marquette University, james.trebby@marquette.edu

Published version. Journal of Applied Business Research, Vol. 17, No. 1 (Winter 2001): 55-60. DOI. (C) 2001 Clute Institute. Used with permission. 


\title{
Investment Performance Comparison Between Roth And Traditional Individual Retirement Accounts
}

\author{
George W. Kuner, (Enail: george.kutner@marqubtte.edu), Marquett Lniversity \\ Lloy⿺ D. Doney, (Email: lioyd.doney@marquette.edu), Marquetre Universiry \\ James P. Trebby, (Email: james.trebby@marquete edu), Marquerte University
}

\begin{abstract}
Alstract
With the recent introduction of the Roth Individual Retrement Account (IRA) along with a significantly improved Traditional IRA, there has been considerable interest in comparing the performance of these investment vehicles. Some confusion regarding these comparisons has evolved. In this paper we show that this confusion may be attributed to scale and tax differences between the two investment vehicles. We adjust for these differences by focusing on the after-tax rat -of-retum on investment for each IRA vehicle. We fud that performance depends crucially on the relationship between an individul's tax rates of the time of investment and at the time of withdrawal.
\end{abstract}

\section{Introduction}

W

ith the introciuction of the Roth Individual Retirement Account (IRA) in 1997 along with a significantly improved Traditional IRA, the long-standing latent interest in these investment vehicles has reappeared. Coupled with the lact that the U.S. population is aging and the increased emphasis on self-directed retirement plaming, the IRA continues to enyoy increasing popilarity and importance. With this success; however, new questions have energed. Many of these questions have focused generally on a comparison between the Roth and Traditional IRAs as retirement vehicles.

These questions have been widely discussed in the iterature and popular press. For example, Johnson (1999) and Stevens (1999) focused or

Readers with comments or questions are encouraged to contact the authors wia email. whether one should convert an existing Traditional IRA to a Roth IRA. Which IRA is better for estate planning purposes has been addressed by Anhony (1999) and Kilpatrick (1999). Finally, Shanney-Saborsky (1999) rouched on which IRA is a better investment vehicle. The fundamental reason these questions have emerged is that the Roth and Traditional IRAs provide significantly different tax incentives.

The Traditional IRA is a taxable investment that provides an immediate tax deduction in the arrount of the sum invested subject to linitations. However, any withdrawals including the initial amounts invested are taxable as they occur. In effect, there are two tax savings benefirs from investing in a Traditional IRA. There is an immediate up-front deduction; and second, any future earnings are not taxed until the funds are withdrawn. For example, if one invests $\$ 2000$ in a Tracitional $\mathbb{R A}$ and is in a 40 percent marginal tax bracket (i.e. from federal, state, and 
local taxes), the immediate tax savings would be $\$ 800$. Moreover, taxes on any future eamings as well as the $\$ 2000$ invested are postponed until withdrawals occur. The Roth IRA, on the other hand, is a nontaxable investment. That is to say that, unlike the Traditional IRA, there is no immediate tax savings benefit; however, the total account including the investment amounts and any future earnings are never subject to taxes, even if withdrawn.

The purpose of this paper is to compare the Traditional IRA with the Roth IRA from an after-tax investment point of view. The most appropriate investment performance measure is the after-tax rate-of-renurn on investment. The analysis reveals that which IRA is a better investment depends crucially on an individual's tax rates at the time funds are invested as well as at the time funds are withdrawn. Specifically, this analysis finds that the Traditional IRA will have a higher after-tax return-on-investment if the individual's tax rate at the time of withdrawal is less than the individual's tax rate at the time of invesment. On the other hand, if the individual's tax rate at the time of withdrawal is greater than the tax rate at the time of investment, the Roth IRA will perform better. If the individual's tax rates at the times of investment and withdrawal are the same, both IRAs will perform equally as well.

This paper is organized as follows. The next section of this paper discusses dollar accumulations in the two IRA vehicles. This is followed with a discussion of IRA after-tax returns. Sensitivity of IRA returns with respect to the various input parameters is ther investigated. A discussion of IRA choice follows. Finally, conclisions and suggestions for future research are presented.

\section{IRA Accumulations}

Much of the confusion regarding the performance of both the Roth and Traditional IRAs is a consequence of focusing on the accumulation amounts for each investment vehicle rather than on the return-on-investment. The difficuily stems from the fact that the Roth and Traditional IRAs are taxed differently as described above.

To see this, consider a $\$ 2000$ investment in a Roth IRA. This IRA provides no immediate tax benefit, but rather, the initial investment arnount and any future earnings are never taxed, even withdrawn. Suppose then, one invesis the $\$ 2000$ for ten years with an annual rate-ofreturn of 10 percent. The accumulated amount would be $\$ 5187$, which is not taxable. Alternatively, if one invests $\$ 2000$ in a Traditional IRA, the accumulated amount would also be $\$ 5187$. However, this amount is taxable and would be less than the Roth IRA accumulation on an aftertax basis. Assuming the individual's tax rate is 40 percent, the after-tax accumulation would only be $\$ 3112$. However, the up-front tax savings on the Traditional IRA could also be invested in a taxable account and, assuming a 40 percent tax rate, the $\$ 800$ would grow to $\$ 1433$ after taxes in ten years. Therefore, the rotal Traditional IRA after-tax accumulation would be \$4545, which is still less than the Roth IRA accumulation. Consequently, the Roth IRA would be perceived as a better investment on the basis of after-tax accumulations.

We can formalize these arguments as follows. Letting

$$
\begin{aligned}
& N=\text { the number of years until funds are with- } \\
& \text { drawn } \\
& R=\text { the annual rate-of-return on IRA (before } \\
& \text { taxes) } \\
& A=\text { dollar amount invested } \\
& T=\text { individual tax rate }
\end{aligned}
$$

Then, an investment of $\$ A$ in a Roth IRA would accumulate to $A(1+R)^{N}$ in $N$ years. Alternatively, an investment of $\$ A$ in a Traditional IRA would accumulate to $A(1-T)(1+R)^{N}$ on an aftertax basis. However, the Traditional IRA upfront tax savings would accumulate to: $A T[1+R(1-T)]^{N}$. Thus, the total Traditional IRA and initial tax-savings would accumulate to:

$$
\text { Total Trad }=\mathrm{A}(1-\mathrm{T})(1+\mathrm{R})^{\mathrm{N}}+\mathrm{AT}\left[1+\mathbb{R}_{(1-T)}\right]^{\mathrm{N}}
$$


The ret amoun, Roth accumulation less total Traditional accumulation, would be:

$$
\begin{aligned}
\text { Net } & =\text { Roth }- \text { Traditional } \\
\text { Net } & =A(1+R)^{\mathrm{N}}-\text { Totaltral } \\
& =(1+R)^{N}-\left[1+R(1-T) T^{N}\right\} A T \\
& >0 \quad \text { for al } T>0
\end{aligned}
$$

Roth and Traditional accumulations are presented in Tables 1 and 2 using different input parameters. The tables reveal that if an individual's tax rate remains constant, the after-tax accumulation in a Roth IRA will always be greater than the after-tax accumulation for a Traditional IRA invesment. Thus, the perception is that the Roth IRA is a better investment vehicle.

\section{RA Dinvestment Returms}

Although the previous section presents a convincing argument indicating that the Roth IRA should be the better investment vehicle, this section investigates this proposition further. The previous discussion found that the Roth IRA accumulations will always be larger than the Traditional IRA accumulations. However, the results rest on two important assumptions. First, the Traditional IRA accumulation includes the upfront tax savings as an investment even though it is not apart of the IRA. Second, the individual investor tax rate is assumed to remain the same at both the time of investment and at the time of withdrawal.

These two assumptions are most certainly inappropriate for comparing the two IRA investment vehicles. The first assumption includes the tax savings accurrulation as part of the IRA accumulation. However, the tax savings is not part of the IRA and it is higlly unlikely, from a practical manner, that any investor would include it as such. The correct interpretation is to recognize that, with the differential tax treatment, the two IRA investments will necessarily differ in scale. The Traditional IRA initial net investment amount will be less than the Roth IRA investment amount by the size of the tax savings. With differences in the scale of the investments, it is crucial to compare them on the basis of their after-tax rates-of-return. Second, the assumption that the individual rax rates at the times of invesment and withdrawal are the same is cleariy inappropriate. Although reasons for this are obvious, this reality will be discussed in a later section of this paper. In any event, a proper comparison should certainly allow for the possibility of tifferential tax rates at the times of invesment and withdrawal.

We now compare the Roth and Traditional IRAs cr the basis of their after-tax rates-ofreturn. Letting

$$
\begin{aligned}
R= & \text { annual rate-of-retum on IRA funds } \\
N= & \text { number of years until funds are withdrawn } \\
A= & \text { amount invested in } 1 R A \\
T & =\text { individual tax rate at the time of investment } \\
T_{w}= & \text { individual tax rate at the time of with- } \\
& \text { drawal }
\end{aligned}
$$

Then, since the Roth IRA is not taxable, the after-tax rate-of-rewrn is defined as:

$$
\begin{aligned}
& \left(1+R_{R e c h}\right)^{N}=A(I+R)^{N} / A=(1+R)^{N} \\
& R_{r e o c h}=R
\end{aligned}
$$

Thus, the Roth IRA return is simply the rate-ofreturn earned on the fund. This makes sense since the Roth IRA is never taxable.

For the Traditional RA, the after-tax rateof-return is defined as:

$$
\left(1+R_{\mathrm{Tad}}\right)^{2 / 2}=\mathrm{A}(1+\mathrm{R})^{\mathrm{N}}\left(1-\mathrm{TW}_{\mathrm{W}}\right) / \mathrm{A}(1-\mathrm{T})
$$

or

$$
\mathrm{R}_{\text {Trad }}=(1+\mathrm{R})[(1-\mathrm{Tw}) /(1-\mathrm{T})]^{1 / \mathrm{N}}-1
$$

Comparing equarions (1) and (2), we car: see that:

$$
\begin{aligned}
& \mathrm{R}_{\mathrm{Trad}}>\mathrm{R} \text { Roth } \text { if } \mathrm{Tw}<\mathrm{T} \\
& \mathrm{R}_{\text {rral }}<\mathrm{R}_{\text {Roth }} \text { if } \mathrm{Tw}<\mathrm{T} \\
& \mathbf{R}_{\mathrm{Trad}}=\mathrm{R}_{\mathrm{Roth}} \text { if } \mathrm{Tw}=\mathrm{TI}
\end{aligned}
$$

Therefore, a comparison of a Roth IRA with a Traditional IRA on the basis of after-tax rates-ofreturn shows that performance is independent of the amount invested, but depends crucially on the relationship between the individua' 's tax rates at the times of investment and withdrawal. The Traditional IRA performs better (worse) than the 
Table 1

After-tax IRA Accumulations

\$2,900 Investment, 10 Percent Return

Years to

\begin{tabular}{|c|c|c|c|c|c|c|c|c|}
\hline Withdrawal & \multicolumn{2}{|c|}{5} & \multicolumn{2}{|c|}{10} & \multicolumn{2}{|c|}{20} & \multicolumn{2}{|c|}{30} \\
\hline Tax Rate & Roth & Traditional & Roth & Traditional & Roth & Traditional & Roth & Traditional \\
\hline $20 \%$ & 3,221 & 3,165 & 5,187 & 5,014 & 13,455 & 12,628 & 34,899 & 31,944 \\
\hline $30 \%$ & 3,221 & 3,096 & 5,187 & 4,812 & 13,455 & 11,740 & 34,899 & 28,997 \\
\hline $40 \%$ & 3,221 & 3,003 & 5,187 & 4,545 & 13,455 & 10,639 & 34,899 & 25,534 \\
\hline $50 \%$ & 3,221 & 2,887 & 5,187 & 4,223 & 13,455 & 9,381 & 34,899 & 21,771 \\
\hline
\end{tabular}

Table 2

After-tax IRA Accumulations

$\$ 2,000$ Investment, 10-Year Investment

\begin{tabular}{|c|c|c|c|c|c|c|c|c|}
\hline \multirow{2}{*}{$\begin{array}{l}\text { Returii } \\
\text { Tax Rate }\end{array}$} & \multicolumn{2}{|c|}{$10 \%$} & \multicolumn{2}{|c|}{$20 \%$} & \multicolumn{2}{|c|}{$30 \%$} & \multicolumn{2}{|c|}{$40 \%$} \\
\hline & Roth & Traditional & Roth & Traditional & Roth & Traditional & Roth & Traditional \\
\hline $20 \%$ & 5,187 & 5,014 & 2,383 & 11,671 & 27,572 & 25,495 & 57,85 & 52,705 \\
\hline $30 \%$ & 5,187 & 4,812 & 12,383 & 10,893 & 27,572 & 23,337 & 57,851 & 47,579 \\
\hline $49 \%$ & 5,187 & 4,545 & 12,383 & 9,915 & 27,572 & 20,730 & 57,851 & 41,586 \\
\hline $50 \%$ & 5,187 & 4,223 & 12,383 & 8,785 & 27,572 & 17,831 & $57,85 !$ & 35,117 \\
\hline
\end{tabular}

Roth IRA if the tax rate at withdrawal is less (greater) than the tax rate at the time of investment. If the tax rates are the same then the Roth and Traditional IRAs perform equally as well. Table 3 provides a sample of acrual calculated returns for both a Roth and Traditional IRA for different representative individual tax rates and different times of withdrawal. The average annual return (before taxes) is assumed to be 10 percent.

We now investigate how the after-tax rateof-return on the Traditional and Roth IRAs vary with respect to the different input parameters. Letting $X=(1-T w) /\left(1-T_{1}\right)$, we can write:

$$
\operatorname{RTrab}_{\mathrm{T}}=(1+\mathrm{R}) \mathrm{X}^{1 / \mathrm{N}}-1
$$

$\mathrm{X}$ represents the relative tax rate ratio. We first compute the sensitivity of R Rrad with respect to $\mathrm{X}:$

$$
\mathrm{dRrad}_{\mathrm{dX}}=(1+\mathrm{R})(1 / \mathrm{N}) \mathrm{X}^{1 / \mathrm{N}-1}>0
$$

We next compute the sensitivity of Rrad with respect to the time of withdrawal $N$. Using the property $d / d x\left(a^{u(x)}\right)=a^{i} \ln (a)(d u / d x)$, see Selby (1969) for example, we can write:

$$
\mathrm{dR}_{\mathrm{Trad}} / \mathrm{dN}=(1+\mathrm{R}) \mathrm{X}^{\mathrm{l} / \mathrm{N}} \ln (\mathrm{X})\left(-1 / \mathrm{N}^{2}\right)
$$

The sign of this expression depends upon the value of $X$ as follows:

$$
\begin{array}{rlrl} 
& <0 & \text { if } \mathrm{X}>1 \\
\mathrm{dR}_{\mathrm{Trad} / \mathrm{dN}} & =0 & \text { if } \mathrm{X}=1 \\
& >0 \text { if } \mathrm{X}<1
\end{array}
$$

Note again that $\mathrm{dR} \mathrm{R}_{\mathrm{n}} / \mathrm{dN}$ is zero. Therefore, equation (4) can be interpreted as follows. When the Roth IRA performs better than the Traditional IRA, that is $X<1$ (see (3)), then the Traditional IRA return performance approaches that of the Roth. In the linit that $N \rightarrow \infty$, notice that $R_{T r a d} \rightarrow R_{\text {Roti }}$ and the two IRAs are equivalent. However, in the case that the Tradi- 
Table 3

After-tax Percentage Returns an Traditional IRA* (Time of Withdrawal Varies)

Nominal Return Per Year: 10\%, Amount lnvested (Before-tas) $\$ 2,000$

Tax Rate at

Time of lnyestment

$19 \%$

$29 \%$

$30 \%$

$40 \%$

$50 \%$
Tax Rate at Time of Withdrawal

$10 \%$

10.00

10.00

10.00

10.00

11.30

10.65

10.43

10.32

12.80

11.39

10.93

10.69

$\lcm{4.55}$

12.25

11.50

11. 12

16.66

13.28

12.18

11.63

$\begin{array}{llll}20 \% & 30 \% & 40 \% & \underline{50 \%} \\ 8.71 & 7.27 & 5.63 & 3.72 \\ 9.35 & 8.63 & 7.79 & 6.81 \\ 9.57 & 9.08 & 8.52 & 7.87 \\ 9.68 & 9.31 & 8.89 & 8.40 \\ 10.00 & 8.54 & 6.88 & 4.95 \\ 10.00 & 9.27 & 8.43 & 7.45 \\ 10.00 & 9.51 & 8.95 & 8.29 \\ 10.00 & 9.63 & 9.21 & 8.72 \\ 11.48 & 10.00 & 8.32 & 6.36 \\ 10.74 & 10.00 & 9.16 & 8.16 \\ 10.49 & 10.00 & 9.44 & 8.77 \\ 10.37 & 10.00 & 9.58 & 9.08 \\ 13.21 & 11.71 & 10.00 & 8.01 \\ 11.59 & 10.85 & 10.00 & 9.00 \\ 11.06 & 10.57 & 10.00 & 9.33 \\ 10.79 & 10.42 & 10.00 & 9.50 \\ 15.29 & 13.76 & 12.02 & 10.00 \\ 12.62 & 11.87 & 11.01 & 10.00 \\ 11.74 & 11.24 & 10.67 & 10.00 \\ 11.30 & 10.93 & 10.50 & 10.00\end{array}$

* Note: Roth IRA After-tax Return is $10 \%$ in all Cases

tional IRA performs better that the Roti (i.e. $X$ $>1$, then the performance of the Traditional IRA decines relative to the Roh as $\mathrm{N}$ gets large. In the limit as $\mathrm{N} \rightarrow \infty$, the Rras will approach RRoth (from above). Finally, if the two IRAs are equivalent (i.e. $X=1$ ), then like the Roth, the Traditional $\mathbb{R A}$ performance does not change with $N$. All in all, as the withdrawal time is delayed, the two IRAs become closer in return performance.

\section{Which IRA is Better?}

The analysis presented above indicates that, on the basis of after-tax return on investment, the Traditional IRA performs better (worse) than the Roth IRA when the individual tax rate at the time of investment is less (greater) than the individual's tax rate at the time of withdrawal. So. which IRA is better depends on the relationship between these individual tax rates.

For most individuals, one can argue persuasively that the tax rate at the time of investment will be greater than the tax rate at the time of withdrawal. There are a number of reasons why this statement is likely to be true. First, most individuals will have lower income during retirement than during their working years. The design of many retirement plars favors this sination. Second, many individuals move in their retirement years to states which tend to have lower individual tax rates. Table 4 shows individual income tax rates for selected states. There is a terdency for people to work in states with higher tax rates. Third, a person can and will most probably "time" the IRA investment decision to coincide with periods of high income. Fourth, 
Table 4

Selected State Individual Tax Rates

For the Year 1999

\begin{tabular}{lcr} 
State & \multicolumn{2}{c}{$\begin{array}{c}\text { Percentage Tax Rates } \\
\text { High }\end{array}$} \\
Arizona & $\frac{\text { Lw }}{2}$ & 5.04 \\
California & 1 & 9.03 \\
Florida & No State Income Tax \\
Nevada & No State Income & Tax \\
New York & 4 & 6.85 \\
Texas & No State Income Tax \\
Washington & No State Income Tax \\
Wisconsin & 4.77 & 6.77
\end{tabular}

within limits one can "time" IRA withdrawals with periods of lower income when the need is highest. Finally, for a variety of reasons, the general expectation is that tax rates will probably fall in the foreseeable future. For all of these reasons, most individual tax rates will be lower at the time of withdrawal than at the time of investment. As such, the Traditional IRA will most likely be the preferred investment choice.

\section{Conclusions}

In this paper we show that which IRA, Roth or Traditional, is better from an after-tax return on investment viewpoint depends crucially on the relationship between an individual's tax rates at the time of investment and at the time of withdrawal. We also emphasize the importance of focusing on the return on investment. Since the two IRAs are treated difierently with respect to taxes, a proper comparison must not ignore the differences in scale of the two investments. Finally, we argue that indivicual tax rates at the time of withdrawal will generally be less than individual tax rates at the time of investment; and as a consequence, the Traditional IRA will be a better investment vehicle for most individuals.
Suggestions for Future Research

There are at least two potentially fruitful areas of future research related to this topic that may provide additional insight. One would be to focus on theoretical aspects not aldressed in this analysis. Specifically, although allowance for differential tax rates is incorporated in this study, this analysis assumes one investment and one withdrawal. However, multiple withdrawals (with a series of different tax rates) of a single investment may be more realistic and may provide further insight. Observation of how the IRAs differ in withdrawal restrictions and how each can be used as a tool in estate planning could be incorporated into the analysis. These subtle differences are virtually ignored in this present study.

A second area of focus could be an empirical investigation of current investor behavior regarding IRA choice. IRA choice could be investigated demographically. Data collection could employ the careful use of either surveys or isolated samples. Trends in individual tax rates both before and during retirement could also be investigated.

\section{References}

1. Anthony, Joseph, "Pass it on," Worth, July/August 1999, pages 83-84

2. Johnson, Linda M., "Roth IRAs: Converting, recharacterizing, and reconverting," Journal of Accountancy, Vol. 188, No. 2, August 1999, pages 75-79

3. Kilpatrick, Bob G., "Income tax strategies for lump-sum distributions," Joumal of Taxation, Vol. 91, Issue 2, page 95

4. Shanney-Saborsky, Regina, "Planning Issues in using the Roth IRA," Journal of Financial Planning, Denver, June 1999, Vol. 12, Issue 6, pages 32-33

5. Selby, Samuel, Standard Mathematical Tables, The Chemical Rubber Company, $17^{\text {th }}$ Edition, 1969

6. Stevens, Kevin T., "Timing the Roth IRA Conversion," Joumal of Accountancy, July 1999, Vol. 188, Issue 1, pages 73-77 